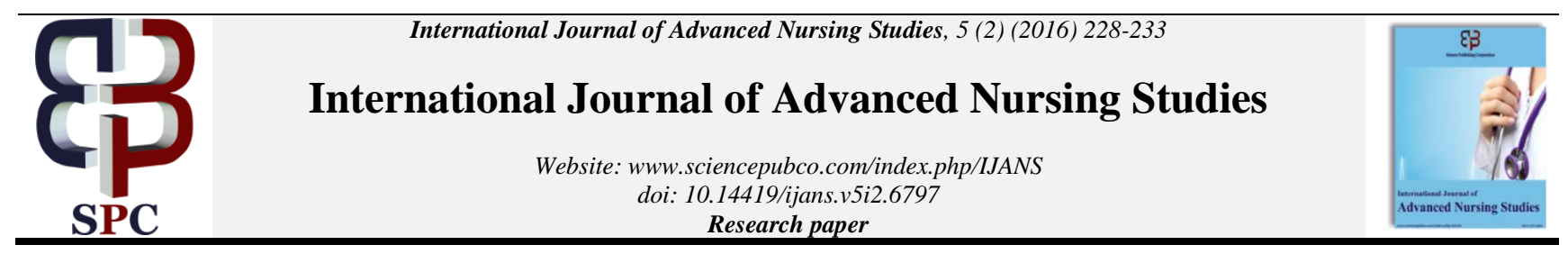

\title{
Oral motor intervention accelerates time to full oral feeding and discharge
}

\author{
Atiat A Osman 1*, Eman S Ahmed ${ }^{2}$, Hend S Mohamed ${ }^{2}$, Farok E Hassanein ${ }^{3}$, Debra Brandon ${ }^{4}$ \\ ${ }^{1}$ Pediatric Nursing, Faculty of Nursing, South valley University, Egypt \\ ${ }^{2}$ Pediatric Nursing, Faculty of Nursing, Assiut University, Egypt \\ ${ }_{3}^{3}$ Pediatrics, Faculty of Medicine, Assiut University, Egypt \\ ${ }^{4}$ Pediatric Nursing, School of Nursing, Duke University, USA \\ *Corresponding authorE-mail:Atiat.osman@duke.edu
}

\begin{abstract}
Background: A Survival rate in early preterm infants has increased over the last 30 years, but many of these infants have medical and developmental problems. Difficulty with feeding and poor nutrition complications are common, which contribute to their readmission and morbidity.

Objective: To purpose of this study was to assess whether an oral motor stimulation intervention can decrease the time to achieve full oral feeding and shorten the length of hospitalization in preterm infants.

Design and Methods: Seventy-five preterm infants born at 30 to $\leq 32$ weeks gestational age were randomly assigned to three groups to assess intervention effects. Two groups received the intervention once per day with varying different intervention doses across time, while the control group received a sham intervention.

Results: The time needed to reach full oral feeding was significantly different among groups $(\mathrm{P}<0.0001)$. Infants who received the intervention from initiation of tube feedings until full oral feeding (high dose) gained full oral feedings and were discharged from the hospital earlier than the low dose and control groups $(\mathrm{P}=0.0001)$. Infants in the high dose group were discharged 6 days earlier than controls and 4 days earlier than the low dose group.
\end{abstract}

Conclusion: Oral motor stimulation intervention accelerated the time to full oral feeding and decreased the length of hospital stay.

Keywords: Premature Infants; Oral Feeding; PIMO; Oral Stimulation; Length of Hospital Stay.

\section{Introduction}

Every year, an estimated 15 million infants are born preterm, and this number is growing. The increasing survival of premature infants in the past 30 years (Kramer, Demissie et al. 2000, Jadcherla and Shaker 2001 , Kelly 2006) has given attention to the cost of hospital care (Simpson, Schanler et al. 2002). In 2003 in the U.S. more than 2 billion dollars could have been saved annually if preterm infants were discharged three days earlier (Martin, Hamilton et al. 2003). Timing of infant hospital discharge is often dependent upon successful oral feeding with premature infants requiring longer hospital stays to become proficient (Davies, Haxby et al. 1979, Resch, Pasnocht et al. 2005, American Academy Of Pediatrics 2008). Therefore, interventions to promote acquisition of oral feeding in preterm infants are needed.

Unlike full-term infants, the majority of preterm infants are not able to begin oral feeding (bottle or breast) immediately after birth due to low oral muscle tone, insufficient control, and poor coordination between sucking, swallowing, and breathing (Lau, Alagugurusamy et al. 2000). Moreover additional medical interventions can disrupt and weaken sensory motor function including intubation, tube feeding, and suctioning (Dodrill, McMahon et al. 2004). Typically infants require enteral tube feedings until oral feedings can be introduced between 32 and 34 weeks gestational age (GA) (Wolff 1968). Gavage feedings deprive an infant of sensory stimuli, impairing motor-oral development, possibly altering the coordination of sucking, swallowing, and breathing and thus further impairing oral feeding (Garber 2013). Therefore, therapeutic interventions to support oral motor skill competence could facilitate the acquisition of full oral feeding.

Different oral stimulation strategies such as stroking lips, cheeks massage or non-nutritive sucking (NNS) have been used to enhance oral feeding skills (Measel and Anderson 1979, Fucile, Gisel et al. 2002, Hwang, Vergara et al. 2010, Lessen 2011, Lyu, Zhang et al. 2014). Previous research suggests that oral motor interventions may shorten the time from introduction of oral feeding to independent oral feeding, by improving oral feeding performance in premature infants (Arvedson, Clark et al. 2010, Lessen 2011, Tian, Yi et al. 2015). More recently one oral sensorimotor stimulation intervention targeted input to the oral structures to promote feeding competence (Lessen 2011). However, given the limited data to date and no data from developing countries, the aim of the current study was to evaluate the impact of an oral motor intervention on feeding progression in premature infants.

\section{Methods}

A randomized three group design was used to evaluate the effect of an oral motor intervention on time to full oral feedings. It was hypothesized that a five minute once a day oral motor intervention would result in faster feeding progression to independent oral feeding when compared to infants who received a sham intervention

\subsection{Setting}

The study was conducted at five neonatal intensive care units (NICUs) in Egyptian hospitals, which are: Assuit University Children, Maternity and Children, Assuit General, Health Insurance, and El-Eman. 


\subsection{Subjects}

A convenient sample of 75 clinically stable preterm infants born at 30 to $\leq$ 32 weeks GA were recruited. Infants $<30$ weeks were excluded because in Egypt like elsewhere, the standard of care is to begin oral feeding after 30 weeks (Delaney and Arvedson 2008). In addition, in Egypt, preterm infant survival before 30 weeks GA is low making these preterm infants difficult to be included in the study. Infant's GA was determined by neonatologist's admission Ballard gestational age assessment (Ballard, Khoury et al. 1991). Inclusion criteria also included appropriate for gestational age to excluded possibility of growth restrictions (Alexander, Himes et al. 1996). Infants who (a) had documented or suspected congenital anomalies, (b) were experiencing necrotizing enterocolitis (NEC), (c) had a brain injury (including intraventricular hemorrhage), (d) were receiving assistive ventilation or high-flow nasal cannula more than $4 \mathrm{~L} / \mathrm{h}$, or (e) were clinically unstable per the medical staff were excluded from the study because they have known delays in acquisition of oral feeding or their medical condition precluded their participation in the intervention. The sample consisted of two intervention groups with low and high intervention doses and a control group, each with 25 infants (Fig. 2):

1) Group A, received a 5-minute premature infant oral motor intervention (PIOMI) once per day for 7 consecutive days or until oral feedings were initiated, whichever came first (low dose).

2) Group B, received a 5-minute PIOMI once per day until independent oral feeding was established (high dose).

3) Control group received a sham intervention to keep staff blinded to the infants' group assignment.

Power analysis, effect sizes were calculated for all outcome variables using Cohen's definition. Effect sizes of $0.2,0.5$, and 0.8 were considered small, moderate, and large respectively (Cohen 1992). Data were analyzed using SAS version 9.3 Using mean and standard deviation values from a previous study by Fucile et al (Fucile, Gisel et al. 2002) and a power of $80 \%$ and confidence level of $95 \%$, we required a sample size of 10 for each group.

All infants were randomly assigned to control and experimental groups by three fixed blocks method to ensure that the groups would be equal. The group assignments were unknown to the nursing and medical staff to minimize bias in ordering or providing oral feeding. The study was approved from School of Nursing, Assuit University, Egypt. In addition, managers from each hospital provided their support after reviewing the study proposal. All data collection occurred in Egypt. Approval was also obtained from Duke University, North Carolina, USA where the research was completed.

\subsection{Intervention}

The PIOMI was used to stimulate the oral muscles of the premature infant to enhance their maturation and strength. This stimulation intervention is modeled after the work of Lessen (2011). Good intervention inter- and intra-reliability measured by test retest method is reported in the literature (Goebel. 2010). The intervention includes stroking and pressure to the structures in and around the mouth. The 5-minute stimulation activates muscle contraction with passive movement and resistance to build strength by providing finger stroking and pressure on the lips, cheeks, jaw, and tongue (Beckman 2006, Lessen 2011).

Experimental groups received the 5-minute stimulation intervention once a day for either seven consecutive days (low dose) or until the premature infant was able to consume eight bottles orally in a day (high dose). All infants received the daily intervention immediately before a feeding inside their incubator to minimize the handling required. The first three minutes of the stimulation was focused on stroking oral structures and the last 2 minutes were NNS using a pacifier. If an infant was irritable or not stable before or during the intervention, the intervention was skipped until the infant was stable again. Medical unstable was defined as episodes of oxygen desaturations, apnea, or bradycardia during the intervention. The intervention was completed by the first author. Training on the intervention was completed with the use of detailed training materials developed by Lessen (Lessen 2011). In addition, a pilot study was completed with six infants to test the applicability and feasibility of the intervention.

Infants in control group did not receive any oral motor intervention. They received a sham intervention which included the investigator standing at the bedside during the pre-feeding period with both hands inside the isolette for 5 minutes, using random and fake hand movement to maintain blinding for group assignment.

\subsection{Outcome measures}

Time to full oral feeding, was defined as the number of days from beginning of oral feeding until independent oral feeding was achieved. Independent oral feeding was defined as consuming $100 \%$ of eight oral bottle feedings in a day without intolerance signs such as vomiting, abdominal distention, tachycardia, and tachypnea, or supplement by tube feeding. Eight phases were used to measure infants' feeding progression. These phases included when the infant was able to consume one bottle per day at phase one to eight bottles per day at phase eight and was calculated by the number of full bottles consumed each day. Each phase was successfully completed before the infant could move to the next phase. For example, if an infant progressed to phase three with three bottles per day, and in the following day he only consumed two bottles (phase two), then all of this time frame was categorized as phase two.

Length of hospital stay was defined as the numbers of days from the admission day to the date of discharge. At the study NICUs, there was no required weight or postmenstrual age (PMA) criteria that constrained discharge, but full oral feeding is considered.

Other outcome measures included days of life, PMA and infants' weight through three millstones (introduction of oral feeding, full oral feeding, and discharge).

\subsection{Procedure}

Daily the subjects were assessed to follow their progress, the intervention began on the day of the infant's first tube feeding. The intervention continued for up to one week in Group A (low dose) and until full oral feedings were achieved in Group B (high dose) (Fig. 1). Introduction of oral feeding was the attending physician's decision. Informed consent obtained from parents after explanation the aim of the study.

\subsection{Statistical analysis}

Descriptive statistics were used to describe the sample. A Kruskall-Wallis, test for pairwise comparison was used to assess the outcome variables because of the small sample size $(\mathrm{N}=25)$ in each group and the skewness in the data. The level of significance was set at 0.05 (two-tailed).

\section{Research Design}

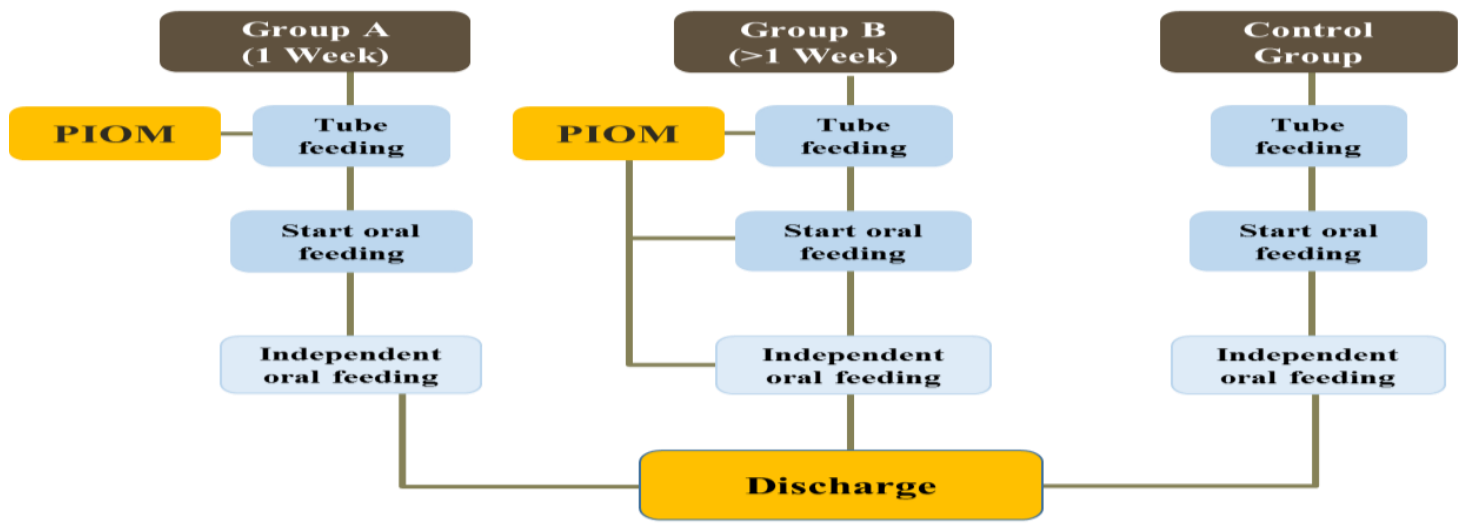

Fig. 1: Experimental Groups Time Line.

*Control Group Received Only Sham Intervention 


\section{Results}

Seventy-five premature infants were included in the study. They had a mean birth weight of 1.5 kilograms \pm 0.2 . Infants' gestational age at birth ranged from 30 to 32 weeks with no statistical differences between the three groups in baseline characteristics (Table 1).

Table 1: Premature Infants' Characteristics

\begin{tabular}{|c|c|c|c|c|c|}
\hline \multirow[b]{2}{*}{ Variables } & \multirow[b]{2}{*}{ Total sample $\mathrm{N}=75$} & \multicolumn{2}{|c|}{ Experimental Group } & \multirow[b]{2}{*}{ Group C Control $\mathrm{N}=25$} & \multirow[b]{2}{*}{ P-Value } \\
\hline & & $\begin{array}{l}\text { Group A (low dose) } \\
\mathrm{N}=25\end{array}$ & $\begin{array}{l}\text { Group B (High dose) } \\
\mathrm{N}=25\end{array}$ & & \\
\hline \multicolumn{6}{|c|}{ Gestational age distribution, $\mathrm{n}(\%)$} \\
\hline 31 weeks & $8(10.7)$ & $2(8.0)$ & $2(8.0)$ & $4(16.0)$ & \multirow{2}{*}{0.8637} \\
\hline 32 weeks & $37(49.3)$ & $14(56.0)$ & $12(48.0)$ & $11(44.0)$ & \\
\hline \multicolumn{6}{|l|}{ Birth weight, kg } \\
\hline Mean \pm SD & $1.5 \pm 0.2$ & $1.5 \pm 0.3$ & $1.5 \pm 0.2$ & $1.5 \pm 0.3$ & \multirow{3}{*}{0.984} \\
\hline $\operatorname{Median}\left(25^{\text {th }}, 75^{\text {th }}\right)$ & $1.5(1.3,1.7)$ & $1.5(1.2,1.7)$ & $1.5(1.3,1.6)$ & $1.4(1.3,1.7)$ & \\
\hline Min, Max & $(1.1,2.1)$ & $(1.1,2.1)$ & $(1.2,1.9)$ & $(1.1,2.1)$ & \\
\hline \multicolumn{6}{|l|}{ Gender, n (\%) } \\
\hline Female & $29(38.7)$ & $11(44.0)$ & $9(36.0)$ & $9(36.0)$ & \multirow[t]{2}{*}{0.8716} \\
\hline Male & $46(61.3)$ & $14(56.0)$ & $16(64.0)$ & $16(64.0)$ & \\
\hline
\end{tabular}

Kruskall-Wallis Test for continuous variables; Fisher Exact Test for categorical variables; two tailed test results with significance set at P $\leq$ 0.05; SD = Standard Deviation; $25^{\text {th }}, 27^{\text {th }}=25^{\text {th }}, 27^{\text {th }}$ percentile; Max, Min $=$ Maximum, Minimum.

\subsection{Feeding progression}

The time to full oral feeding for the total sample was a mean of 10.5 days (S.D.=3.7) with a range from 4 to 19 days. Comparisons among groups revealed that the high dose intervention group achieved independent oral feeding in significantly fewer days when compared to either the low dose intervention or control groups (medians 8,11 , and 13 respectively) $(\mathrm{P}<0.0001)($ Fig 2$)$.

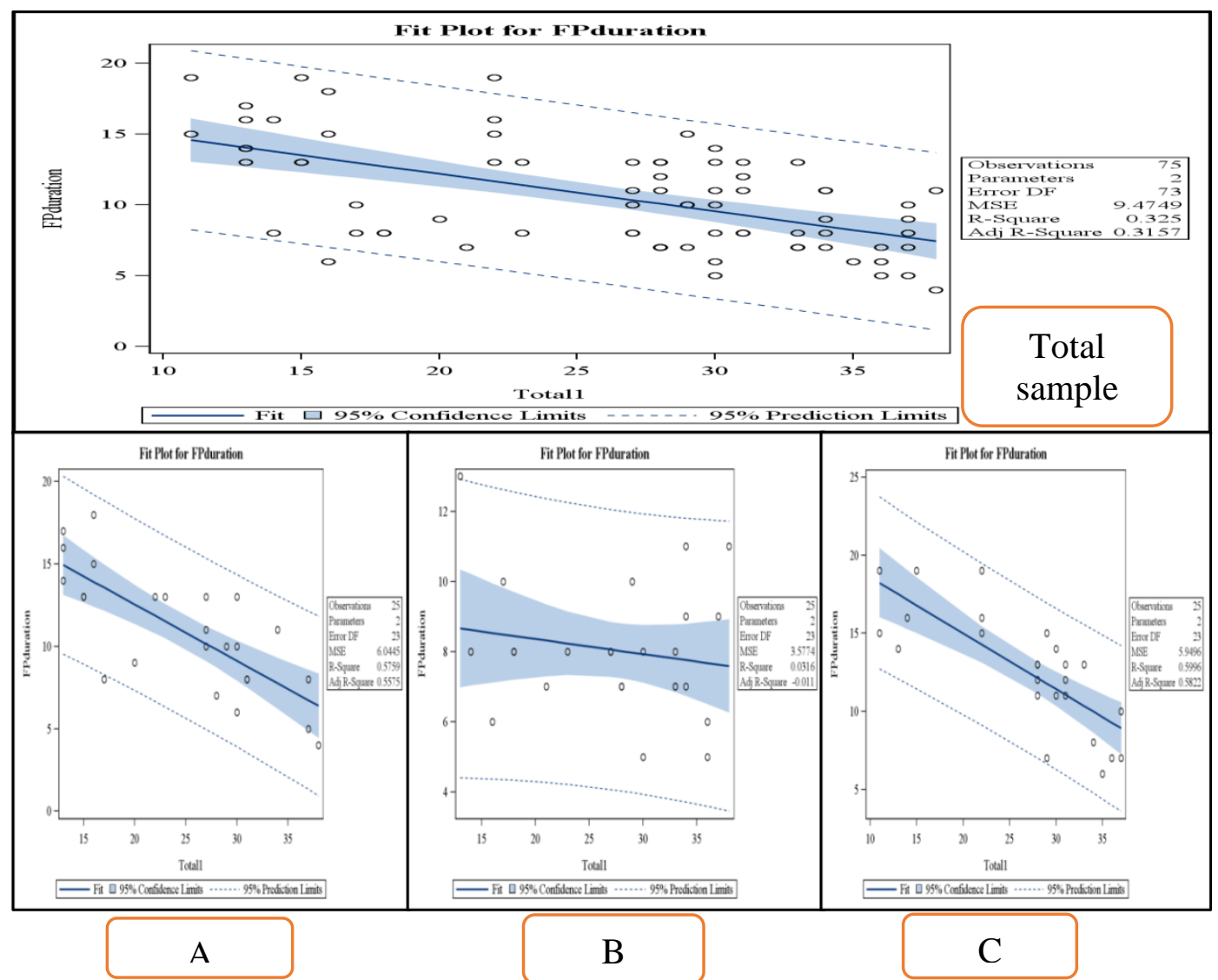

Fig. 2: Feeding Progression Period for Total Sample and Among Each Group. A= Experimental Group Receive Low Dose Intervention; B = Experimental Group Receive High Dose Intervention; C = Control Group.

\subsection{Length of hospital stay}

Infants in the high dose intervention group were also discharged from NICU significantly earlier than the other two groups. They were discharged four days earlier than the low dose intervention group and 6 days earlier than the control group (p=0.0001) (Fig. 3). 


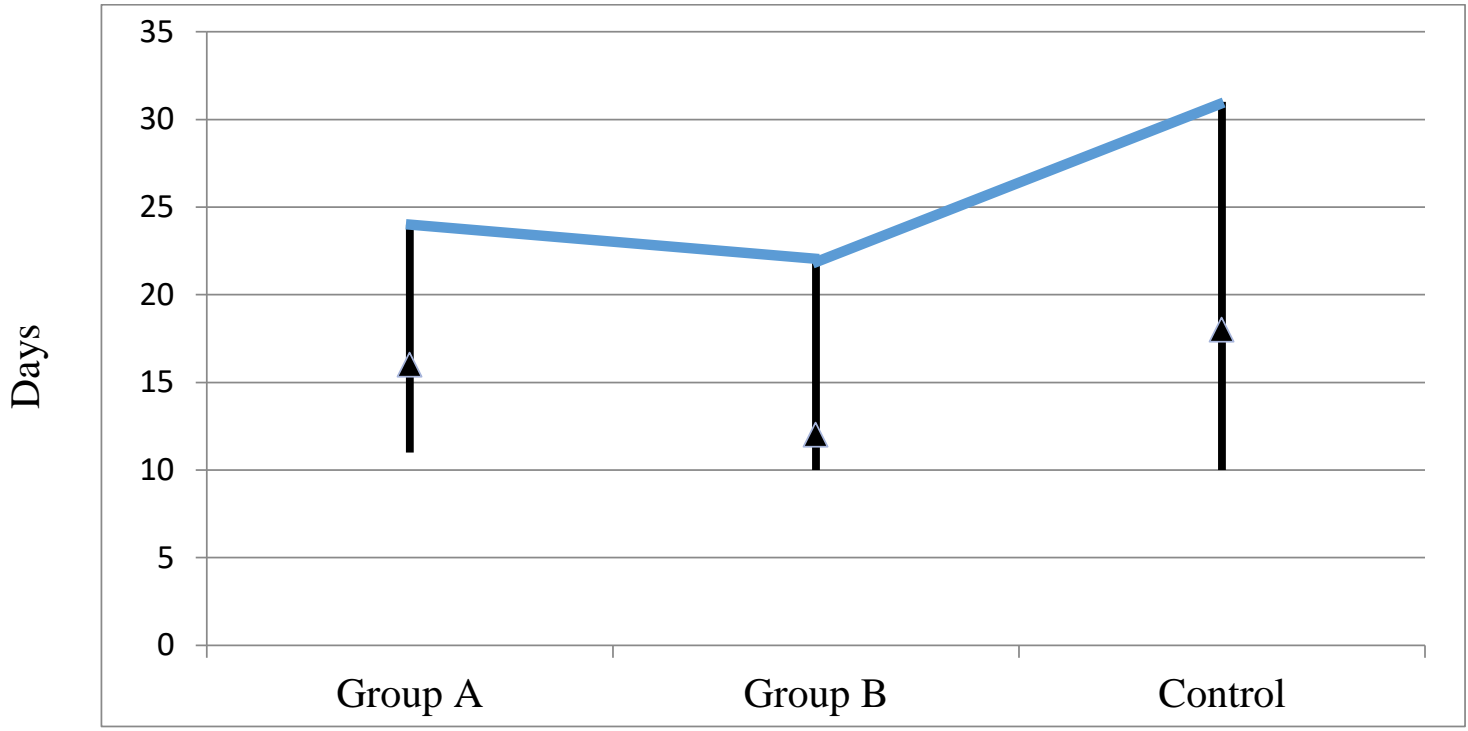

Fig. 3: Median of Hospital Stay, in Days.

\subsection{Other infants' indicators}

There were no significant differences between infants' weight or age at the beginning of oral feeding $(\mathrm{P}=0.698, \mathrm{P}=0.1154)$, but significant differences in weight gain was observed between the initiation of oral feedings and at discharge among groups $(\mathrm{P}=0.0568)$, as the experimental groups in a particular the high dose group gain weight, while control group loss some weight (Table. 2). For age, infants group who received the intervention significantly reach full oral feeding younger than controls (P < 0.0001) (Fig. 4). High dose group gain full oral feeding when they were aged about 11 days PMA, in comparison controls were 17 days PMA (Mean \pm SD; $11.4 \pm 1.9,16.7 \pm 4.2$ respectively).

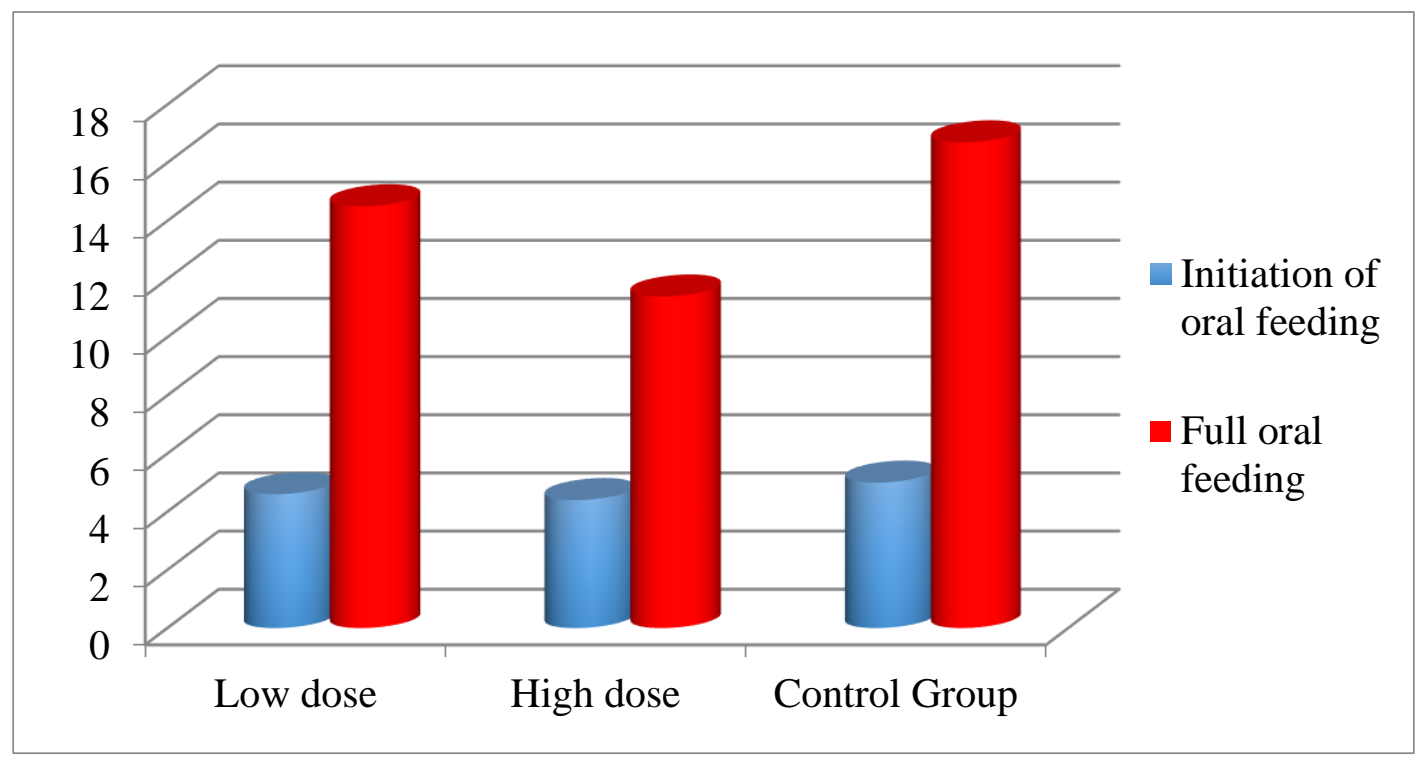

Fig. 4: Premature Infants' Days of Life during Feeding Progression.

Table 2: Infant Weight Gain through Study Groups

\begin{tabular}{llll}
\hline & $\begin{array}{l}\text { Experimental Group } \\
\text { Group A } \\
\text { Leight gain }\end{array}$ & $\begin{array}{l}\text { Group B } \\
\text { High Dose } \\
\mathrm{N}=25\end{array}$ & $\begin{array}{l}\text { Control Group (C) } \\
\mathrm{N}=25\end{array}$ \\
\hline Weight gain, kg & $0.05 \pm 0.18$ & $0.10 \pm 0.23$ & $-0.04 \pm 0.11$ \\
Mean \pm SD & 0.04 & 0.05 & 0.00 \\
Median $\left(25^{\text {th }}, 75^{\text {th }}\right)$ & $(0.09,0.16)$ & $(-0.04,0.12)$ & $(-0.12,0.04)$ \\
Min, Max & $(-0.24,0.44)$ & $(-0.16,0.82)$ & 0.0568 \\
\hline
\end{tabular}

Kruskall-Wallis Test used; A posteriori Wilcoxon Two-Sample Test for Pairwise Comparison; two tailed test result with significance set at $\mathrm{P} \leq 0.05$; SD = Standard Deviation; $25^{\text {th }}, 27^{\text {th }}=25^{\text {th }}, 27^{\text {th }}$ percentile; Max, Min $=$ Maximum, Minimum; Summary of Pairwise Comparisons: $(B>A)>C$.

\section{Discussion}

The findings from this study provided additional evidence that an oral stimulation intervention can decrease the time to full oral feeding and decrease hospital length of stay. In addition, infants who were exposed to the intervention throughout their feeding progression did better than the infants receiving a more limited intervention or the control group. Infants who received the high dose intervention also gained more weight across the feeding progression and at hospital discharge suggesting they were able to consume a higher volume and thus more calories. A previous study that used the same intervention for seven consecutive days in a younger group of 19 premature infants (26-29 weeks) found that infants who received the oral stimulation reached full oral feeding five days earlier than the control group, and were discharged from the hospital 2.6 days earlier. Consistent with previous research (Bier, Ferguson et al. 1993, Simpson, 
Schanler et al. 2002, Yildiz and Arikan 2012) infants weight at discharge was not significantly different.

Oral simulation interventions should not only accelerate time to full feedings, but also the time to the introduction of oral feedings. However, there were no differences among any of the groups in this study regarding time of introduction of oral feeding. These findings are understandable given infant participants were stable and therefore could move more quickly from tube to oral feedings. Further, the narrow gestational age range at birth of the recruited infants (at 30 to $\geq 32$ weeks GA) combined with the standard implementation of oral feedings around 31 weeks PMA in Egypt, resulted in all infants beginning oral feeding around the same time. In Egypt the small numbers of infants born at $<30$ weeks precluded the inclusion of a larger age range of infants, but should be considered in future research.

As the intervention accelerate the time to full oral feeding, consequently premature infants discharge earlier. American academy of Pediatric considered full oral feeding as a criterion for discharge in premature infants (American Academy Of Pediatrics 2008). Like similar studies of ora stimulation, the intervention groups had a decreased hospital LOS (Measel and Anderson 1979, Field, Ignatoff et al. 1982, Sehgal, Prakash et al 1990). On average prior studies employed the oral intervention for 7 days. However, in this study infants who received the intervention from initiation of tube feedings to full oral feedings had the shortest length of stay. In contrast, two other studies found no differences in hospital LOS between the oral stimulation and control groups, however, they hypothesized that the lack of universal discharge guidelines may have contributed to the lack of significance (Fucile, Gisel et al. 2002, Bragelien, Rokke et al 2007, Younesian, Yadegari et al. 2015).

The effectiveness of the oral motor intervention may be in part due to the combined stroking and non-nutritive stimulation strategies. The PIOMI increases the strength of the oral motor muscles as it stimulate the motor function, thereby stimulating the anatomical structures needed to engage in competent safe oral feeding. However, research in this area has mixed results; Non-nutritive work is considered by some as a necessary preparatory phase so the premature infant can be competent when nutritive sucking is introduced (Lau, Sheena et al. 1997, Fucile, Gisel et al. 2005, Pinelli and Symington 2005, Pimenta, Moreira et al. 2008, Fucile, Gisel et al. 2011, Lau, Fucile et al. 2012, Younesian, Yadegari et al. 2015). However, other researchers have concluded that NNS did not have obvious improvement on oral feeding progression (Boiron, Da Nobrega et al. 2007 , Bragelien, Rokke et al. 2007). Future research should continue to explore the components, timing and length of oral stimulation interventions.

\section{Conclusion}

Oral motor stimulation in conjunction with non-nutritive sucking decreased time to full oral feedings and hospital discharge for preterm infants and should therefore be considered for implementation in neonatal care units.

\section{Acknowledgments}

I am indebted to Susan G. Silva, Associate Research Professor Duke University School of Nursing. I feel grateful for her valuable assistance, ad vice throughout the work. I am also grateful for her enthusiasm and timely help in overcoming numerous difficulties.

Also I would like to thank parents for cooperation and understanding, and all medical staff in included NICUS with special thanks for the nurse for great support and help.

\section{References}

[1] Alexander, G. R., J. H. Himes, R. B. Kaufman, J. Mor and M Kogan (1996). "A United States national reference for fetal growth." Obstet Gynecol 87(2): 163-168. http://dx.doi.org/10.1016/0029-7844(95)00386-X.

[2] American Academy of Pediatrics (2008). "Hospital Discharge of the High-Risk Neonate." Pediatrics 122(5): 1119-1126. http://dx.doi.org/10.1542/peds.2008-2174.

[3] Arvedson, J., H. Clark, C. Lazarus, T. Schooling and T. Frymark (2010). "Evidence-Based Systematic Review: Effects of Oral Motor Interventions on Feeding and Swallowing in Preterm Infants." American Journal of Speech-Language Pathology 19(4): 321-340. http://dx.doi.org/10.1044/1058-0360(2010/09-0067).

[4] Ballard, J. L., J. C. Khoury, K. Wedig, L. Wang, B. L. EilersWalsman and R. Lipp (1991). "New Ballard Score expanded to in- clude extremely premature infants." J Pediatr 119(3): 417-423. http://dx.doi.org/10.1016/S0022-3476(05)82056-6.

[5] Beckman, D. (2006). "Oral motor assessment and intervention, from." http://www.beckmanoralmotor.com/.

[6] Bier, J. A., A. Ferguson, C. Cho, W. Oh and B. R. Vohr (1993) "The oral motor development of low-birth-weight infants who underwent orotracheal intubation during the neonatal period." Am J Dis Child 147(8): 858-862? http://dx.doi.org/10.1001/archpedi.1993.02160320060020.

[7] Boiron, M., L. Da Nobrega, S. Roux, A. Henrot and E. Saliba (2007). "Effects of oral stimulation and oral support on nonnutritive sucking and feeding performance in preterm infants." Dev Med Child Neurol 49(6): 439-444. http://dx.doi.org/10.1111/j.14698749.2007.00439.x.

[8] Bragelien, R., W. Rokke and T. Markestad (2007). "Stimulation of sucking and swallowing to promote oral feeding in premature infants." Acta Paediatr 96(10): 1430-1432. http://dx.doi.org/10.1111/j.1651-2227.2007.00448.x

[9] Davies, D. P., V. Haxby, S. Herbert and A. S. McNeish (1979) "When should pre-term babies be sent home from neonatal units?" Lancet 1(8122): 914-915. http://dx.doi.org/10.1016/S01406736(79)91386-2.

[10] Delaney, A. L. and J. C. Arvedson (2008). "Development of swallowing and feeding: Prenatal through first year of life." Developmental Disabilities Research Reviews 14(2): 105-117. http://dx.doi.org/10.1002/ddrr.16.

[11] Dodrill, P., S. McMahon, E. Ward, K. Weir, T. Donovan and B. Riddle (2004). "Long-term oral sensitivity and feeding skills of low-risk pre-term infants." Early Hum Dev 76(1): 23-37. http://dx.doi.org/10.1016/j.earlhumdev.2003.10.001.

[12] Field, T., E. Ignatoff, S. Stringer, J. Brennan, R. Greenberg, S. Widmayer and G. C. Anderson (1982). "Nonnutritive sucking during tube feedings: effects on preterm neonates in an intensive care unit." Pediatrics 70(3): 381-384.

[13] Fucile, S., E. Gisel and C. Lau (2002). "Oral stimulation accelerates the transition from tube to oral feeding in preterm infants." J Pediatr 141(2): 230-236. http://dx.doi.org/10.1067/mpd.2002.125731.

[14] Fucile, S., E. G. Gisel and C. Lau (2005). "Effect of an oral stimulation program on sucking skill maturation of preterm infants." Dev Med Child Neurol 47(3): 158-162. http://dx.doi.org/10.1017/S0012162205000290.

[15] Fucile, S., E. G. Gisel, D. H. McFarland and C. Lau (2011). "Oral and non-oral sensorimotor interventions enhance oral feeding performance in preterm infants." Dev Med Child Neurol 53(9): 829 835. http://dx.doi.org/10.1111/j.1469-8749.2011.04023.x.

[16] Garber, J. (2013). "Oral-motor function and feeding intervention." Phys Occup Ther Pediatr 33(1): 111-138. http://dx.doi.org/10.3109/01942638.2012.750864.

[17] Goebel, C. A. (2010). "Reliability measurement of the premature infant oral motor intervention." Retrieved October 22, 2015, from http://digitalcommons.iwu.edu/nursing_honproj/39.

[18] Hwang, Y. S., E. Vergara, C. H. Lin, W. J. Coster, R. Bigsby and W. H. Tsai (2010). "Effects of prefeeding oral stimulation on feeding performance of preterm infants." Indian J Pediatr 77(8): 869 873. http://dx.doi.org/10.1007/s12098-010-0001-9.

[19] Jadcherla, S. R. and R. Shaker (2001). "Esophageal and upper esophageal sphincter motor function in babies." Am J Med 111 Suppl 8A: 64s-68s? http://dx.doi.org/10.1016/S00029343(01)00848-8.

[20] Kelly, M. M. (2006). "The medically complex premature infant in primary care." J Pediatr Health Care 20(6): 367-373. http://dx.doi.org/10.1016/j.pedhc.2006.01.003.

[21] Kramer, M. S., K. Demissie, H. Yang, R. W. Platt, R. Sauve and R. Liston (2000). "The contribution of mild and moderate preterm birth to infant mortality. Fetal and Infant Health Study Group of the Canadian Perinatal Surveillance System." Jama 284(7): 843-849. http://dx.doi.org/10.1001/jama.284.7.843.

[22] Lau, C., R. Alagugurusamy, R. J. Schanler, E. O. Smith and R. J. Shulman (2000). "Characterization of the developmental stages of sucking in preterm infants during bottle feeding." Acta Paediatr 89 http://dx.doi.org/10.1111/j.1651-2227.2000.tb00393.x.

[23] Lau, C., S. Fucile and E. G. Gisel (2012). "Impact of nonnutritive oral motor stimulation and infant message therapy on oral fedding skills of preterm infants." Journal of Neonatal -perinatal medicine 5(4): 311-317.

[24] Lau, C., H. R. Sheena, R. J. Shulman and R. J. Schanler (1997). "Oral feeding in low birth weight infants." The Journal of Pediatrics 130(4): 561-569. http://dx.doi.org/10.1016/S0022-3476(97)70240-3

[25] Lessen, B. S. (2011). "Effect of the premature infant oral motor intervention on feeding progression and length of stay in preterm in- 
fants." Adv Neonatal Care 11(2): 129-139. http://dx.doi.org/10.1097/ANC.0b013e3182115a2a.

[26] Lyu, T.-c., Y.-x. Zhang, X.-j. Hu, Y. Cao, P. Ren and Y.-j. Wang (2014). "The effect of an early oral stimulation program on oral feeding of preterm infants." International Journal of Nursing Sciences 1(1): 42-47. http://dx.doi.org/10.1016/j.ijnss.2014.02.010.

[27] Martin, J. A., B. E. Hamilton and P. D. Sutton (2003). "Births: Final Data for 2002." Centers for Disease Control and Prevention,.

[28] Measel, C. P. and G. C. Anderson (1979). "Nonnutritive sucking during tube feedings: effect on clinical course in premature infants." JOGN Nurs 8(5): 265-272. http://dx.doi.org/10.1111/j.15526909.1979.tb00960.x.

[29] Pimenta, H. P., M. E. L. Moreira, A. D. Rocha, S. C. G. Junior, L. W. Pinto and S. L. Lucena (2008). "Effects of non-nutritive sucking and oral stimulation on breastfeeding rates for preterm, low birth weight infants: a randomized clinical trial." Jornal de Pediatria 84(5): 423-427. http://dx.doi.org/10.2223/JPED.1839.

[30] Pinelli, J. and A. Symington (2005). "Non-nutritive sucking for promoting physiologic stability and nutrition in preterm infants." Cochrane Database Syst Rev (4): Cd001071. http://dx.doi.org/10.1002/14651858.cd001071.pub2.

[31] Resch, B., A. Pasnocht, W. Gusenleitner and W. Muller (2005) "Rehospitalisations for respiratory disease and respiratory syncytial virus infection in preterm infants of 29-36 weeks gestational age." J Infect 50(5): 397-403. http://dx.doi.org/10.1016/j.jinf.2004.06.015.

[32] Sehgal, S. K., O. Prakash, A. Gupta, M. Mohan and N. K. Anand (1990). "Evaluation of beneficial effects of nonnutritive sucking in preterm infants." Indian Pediatr 27(3): 263-266.

[33] Simpson, C., R. J. Schanler and C. Lau (2002). "Early introduction of oral feeding in preterm infants." Pediatr 110. http://dx.doi.org/10.1542/peds.110.3.517.

[34] Tian, X., L.-J. Yi, L. Zhang, J.-G. Zhou, L. Ma, Y.-X. Ou, T. Shuai, Z. Zeng and G.-M. Song (2015). "Oral Motor Intervention Improved the Oral Feeding in Preterm Infants: Evidence Based on a Meta-Analysis With Trial Sequential Analysis." Medicine 94(31): e1310. http://dx.doi.org/10.1097/MD.0000000000001310.

[35] Wolff, P. H. (1968). "The serial organization of sucking in the young infant." Pediatrics 42(6): 943-956.

[36] Yildiz, A. and D. Arikan (2012). "The effects of giving pacifiers to premature infants and making them listen to lullabies on their transition period for total oral feeding and sucking success." J Clin Nurs 21(5-6): 644-656. http://dx.doi.org/10.1111/j.13652702.2010.03634.x.

[37] Younesian, S., F. Yadegari and F. Soleimani (2015). "Impact of Oral Sensory Motor Stimulation on Feeding Performance, Length of Hospital Stay, and Weight Gain of Preterm Infants in NICU." Iranian Red Crescent Medical Journal 17(7): e13515. http://dx.doi.org/10.5812/ircmj.17(5)2015.13515. 